\title{
Do Lowcarb Diets Cause Heart Disease or Cancer?
}

\author{
Richard M Fleming ${ }^{1 *}$, Matthew R Fleming ${ }^{1}$ and Tapan K Chaudhuri ${ }^{2}$
}

${ }^{1}$ FHHI-OmnificImaging-Camelot, USA

${ }^{2}$ Eastern Virginia Medical School, USA

*Corresponding author: Richard M Fleming, Los Angeles, CA, USA

Keywords: FMTVDM; Lowcarb; heart disease; cancer; atkins; pritikin

\section{Introduction}

It is well recognized that coronary artery disease and cancer are the result of inflammatory changes, which occur within the tissues of the body-specifically the walls of the coronary arteries (CAD) and within the specific organ (e.g. breast, colon) tissue in question [1-3] and not the blood. Despite this obvious difference between blood and tissue, medical studies looking at the impact of diets and drugs have primarily utilized changes in qualitative or at best semi-quantitative imaging [4-6], weight and blood tests to monitor presumed changes in heart disease and cancer. However, changes in heart disease and cancer cannot be measured through the mere use of blood tests alone, since these blood tests merely tell us what is happening within the blood and not what is happening in the tissues of the body proper $[7,8]$. Hence, the persistent debate about the consequences of different diets or drugs, and the potential risk for CAD and cancer [9-14] and the persistent doubt and confusion by the public and media [15-18]. Frankly, if I hadn't spent more than three decades working out some of the details and limitations in our knowledge and published studies - based upon what I read in the lay press -I would be just as confused [19-25].
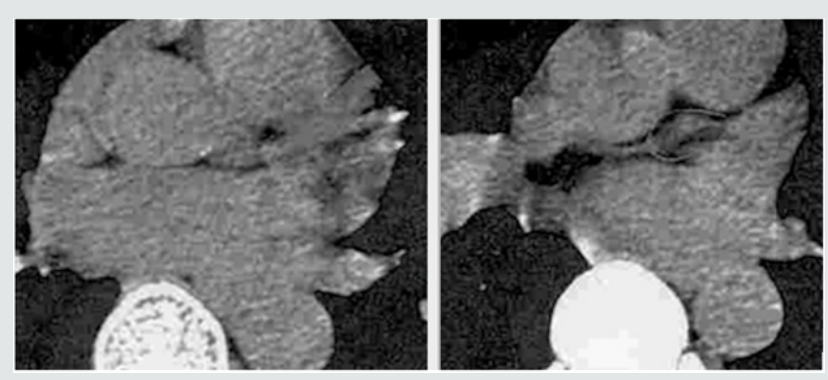

\section{Calcium Score:}

$\begin{array}{lcc}\text { Region } & \text { Agatston } & \text { Volume } \\ \text { LM: } & 0 & 0 \\ \text { RCA: } & 0 & 0 \\ \text { LAD: } & 0 & 0 \\ \text { CX: } & 0 & 0 \\ \text { Total: } & 0 & 0\end{array}$

Figure 1. Coronary Artery Calcium (CAC) study revealed no calcification. 


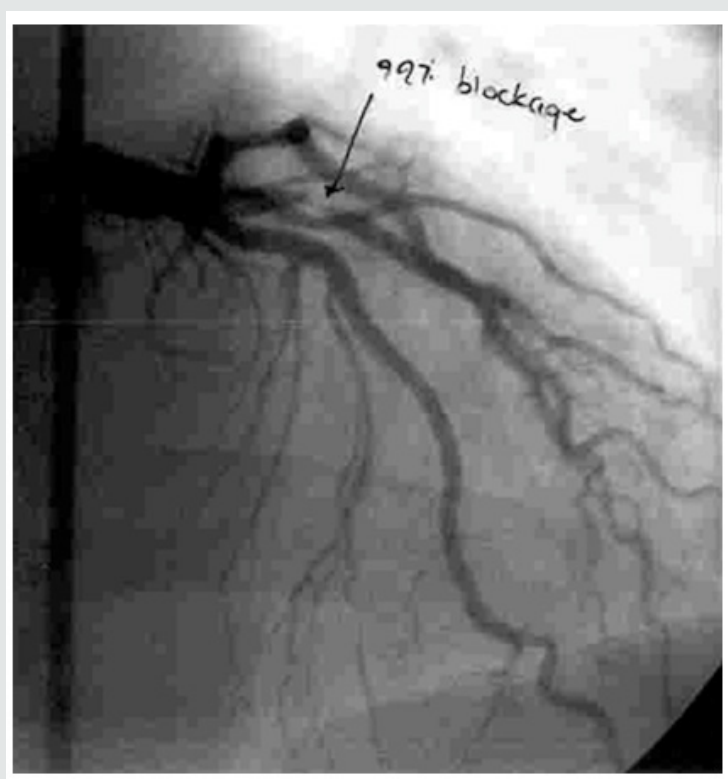

Figure 2. Cardiac catheterization revealed critical Left Anterior Descending (LAD)

Case Example in Point-Consequence or Coincidence?

A middle-aged man with chest discomfort, had per his report, been following a LowCarb diet for six months. His already borderline elevated total blood cholesterol level prior to beginning the LowCarb diet had increased by almost $100 \mathrm{mg} / \mathrm{dl}$ or $2.59 \mathrm{mmol} / \mathrm{l}$ after being on the diet. His physician ordered a Coronary Artery Calcium (CAC) study, shown in Figure 1, which revealed no evidence of calcification. The absence of measurable calcium on a CAC study does not eliminate CAD [1], although, elevated numbers-which are semi-quantitative, can be helpful. In this instance they were not. Following persistent angina chest pain, a coronary arteriogram (cardiac catheterization), shown in Figure 2, was performed reportedly revealing a 99\% narrowing of the proximal part of the patient's Left Anterior Descending (LAD) coronary artery. This was treated with stent placement. The real question here isn't does he have CAD-which he still has despite having stents because having a stent doesn't mean you are now free of CAD, only that you are receiving continued treatment for the CAD-but WHY? Clearly the answer is that he has inflammation within the wall of his LAD. But the more fundamental question is why did this inflammation occur and was the LowCarb diet, which he reported following, the cause of that inflammation or was it merely a coincidence?

\section{Discussion}

Beyond the obvious information from the patients case, including his reported history of changing his diet, the already borderline elevated blood cholesterol level which reportedly increased further on the LowCarb Diet and the CAC study, which failed to detect CAD because, after all, CAC studies only detect calcium-which when present is a good indicator of something going on but the absence of which as seen in this case does not eliminate the question of CAD-the question then becomes, Did the LowCarb diet produce the patients CAD and angina $[19,20]$ ? It is unlikely that in six-months he went from pristine arteries to an almost totally occluded LAD-although as previously documented using Positron Emission Tomography (PET) this could have happened [26]. Notwithstanding this possibility, we simply have no prior information about the state of health of this gentleman's coronary arteries prior to this original cardiac catheterization. Was this the same amount of narrowing that was present prior to the dietary change? Is this worse or better than what existed before? While we now know that Dr. Robert Atkins died with CAD and reportedly had stents placed for treatment years before his death - it is not known whether the Atkins diet was the cause of his CAD. Perhaps it was coincidental, perhaps his heart disease would have been worse without the diet, perhaps it was the cause or perhaps the diet had no effect at all. We also know that Nathan Pritikin died with leukemia and followed the Pritikin vegetarian diet. While much attention has been paid to reports that Pritikin had heart disease diagnosed earlier in life, which was reportedly absent at the time of his death-we truly don't know if the original diagnosis of heart disease was accurate, or not. Perhaps he never had heart disease and simple didn't develop it over time following his diet. The bigger question-one I never hear raised-is What role, if any; did his diet play in his leukemia? Was it the cause, or would he have died earlier had he not been following his diet? Or perhaps the Pritikin diet had no effect on the leukemia.

Despite all the social media, advertising, marketing, Google searches, tweeting, blogs, Facebook postings, and bickering, we will never know the answer to how these diets affected the overall health of-or the role, if any, they played in-Atkins heart disease or Pritikin's cancer. Anyone who tells you otherwise is probably trying 
to sell you something. It is one thing to say there is a correlation and something else altogether to say there is causation [27]. What we do know is inflammation is the cause of heart disease and the early changes associated with cancer [1]. This inflammation is caused by a host of factors, which play different roles in different individuals, based upon their genetic response to environmental factorsenvironmental factors, which include inter alia diet, lifestyle, medications, and smoking. We also know that merely taking blood samples to look for cholesterol levels, or C-reactive protein, or homocysteine, or anything else is ersatz and is not going to tell us what is happening to the coronary arteries themselves or to tissue (e.g. breast) undergoing an environmental barrage on its way to becoming cancer $[7,8]$. If we as physicians are going to talk to our patients, or publish papers in medical journals, or talk to the mediaso the media can write second hand stories, which someone else will write third hand stories about-then we need to get our facts straight and to do that will require that we objectively measure [28] what we are talking about. Until then, we are only doing everyone a disservice by pretending we know exactly what these diets are doing to people. If we are right, then we have just been lucky. If we are wrong-then we are potentially violating our Hippocratic Oath, "Primum non nocere".

\section{Conclusion}

Before we continue to tell people which diets are safe, which are harmful, and which may have no impact on heart disease or cancer, we should first objectively measure the true effect these diets have on the arteries of the heart and the potential areas of the body, where we are concerned about the risk of cancer occurring. Then and only then will we be able to have an intelligent objective conversation with our patients about diets and their causative role in heart disease and cancer.

\section{Acknowledgment}

FMTVDM is owned by first author.

\section{References}

1. Fleming RM (1999) The Pathogenesis of Vascular Disease. In: John C Chang (Ed.), Textbook of Angiology, Chapter 64, Springer Verlag, New York, USA, pp: 787-798.

2. Fleming RM, Fleming MR (2019) The Importance of Thinking about and Quantifying Disease like Cancer and Heart Disease on a "Health Spectrum" Continuum. J Compr Cancer Rep 3(1): 1-3.

3. Fleming RM, Fleming MR, Chaudhuri TK (2019) FMTVDM provides first patented Quantitative Method to accurately Measure both Heart Disease and Breast Cancer on the "Health Spectrum". J Cardiovasc Med Cardiol 6(2): 19-20.

4. Sheikh A (2018) Evolution of Quantification in Clinical Nuclear Medicine: A Brief Overview of Salient Uses and Upcoming Trends. J Nucl Med Radiat Ther 9(5): 375.

5. Fleming RM (2018) FMTVDM Provides the First True SPECT and PET Quantification and Not Virtual Guesstimation Produced by SUV and Extraction Fraction, Yielding First Accurate Theranostic Method. J Nucl Med Radiat Ther 9(5): 118

6. Fleming RM, Fleming MR, McKusick A, Chaudhuri TK (2018) Semi quantification limitations: FMTVDM demonstrates quantified tumor response to treatment with both regional blood flow and metabolic changes. J Nucl Med 59(10): 1643-1644.

7. Fleming RM, Harrington GM (2008) What is the Relationship between Myocardial Perfusion Imaging and Coronary Artery Disease Risk Factors and Markers of Inflammation? Angiology 59(1): 16-25.

8. Fleming RM, Fleming MR, Chaudhuri TK (2019) Changes in Blood Tests Measuring Cholesterol and Inflammation Do Not Correlate with Measured Changes in Coronary Artery Disease. Biomed J Sci \& Tech Res 20(4): 15144-15146.

9. Johnston BC, Zeraatkar D, Han MA, Vernooij RWM, Valli C, et al. (2019) Unprocessed Red Meat and Processed Meat Consumption: Dietary Guideline Recommendations from the Nutritional Recommendations (NutriRECS) Consortium. Ann Intern Med.

10. Vernooij RWM, Zeraatkar D, Han MA, El Dib R, Zworth M, et al. (2019) Patterns of Red and Processed Meat Consumption and Risk for Cardiometabolic and Cancer Outcomes: A Systematic Review and Metaanalysis of Cohort Studies. Ann Intern Med.

11. Zeraatkar D, Johnston BC, Bartoszko J, Cheung K, Bala MM, et al. (2019) Effect of Lower Versus Higher Red Meat Intake on Cardiometabolic and Cancer Outcomes: A Systematic Review of Randomized Trials. Ann Intern Med.

12. Claudia Valli, Montserrat Rabassa, Bradley C Johnston, Ruben Kuijpers, Anna Prokop Dorner, et al. (2019) Health Related Values and Preferences Regarding Meat Consumption: A Mixed Methods Systematic Review. Ann Intern Med.

13. Zeraatkar D, Han MA, Guyatt GH, Vernooij RWM, El Dib R, et al. (2019) Red and Processed Meat Consumption and Risk for All-Cause Mortality and Cardiometabolic Outcomes: A Systematic Review and Meta-analysis of Cohort Studies. Ann Intern Med.

14. Han MA, Zeraatkar D, Guyatt GH, Vernooij RWM, El Dib R, et al. (2019) Reduction of Red and Processed Meat Intake and Cancer Mortality and Incidence: A Systematic Review and Meta-analysis of Cohort Studies. Ann Intern Med

15. Gary Taubes (2002) What if it's all been a big fat lie? The New York Times Magazine, New York, USA.

16. Giles Whittell (2004) Dr. Atkins and the $\$ 40$ bn question-was it something that he ate? Times Online, India.

17. Aseem Malhotra (2018) Why modern medicine is a major threat to public health. The Guardian, UK.

18. Jamie Ducharme (2019) Should You Stop Eating Read Meat? A New Paper Has a Controversial Answer.

19. Fleming RM (2001) Coronary Artery Disease is More than Just Coronary Lumen Disease. Amer J Card 88(5): 599-600.

20. Fleming RM (2003) Angina and coronary Ischemia are the result of coronary regional Blood Flow Differences. J Amer Coll Angiol 1: 127-42.

21. Fleming RM, Fleming MR,Harrington GM, Ayoob KT, Chaudhuri TK, et al. (2018) WEIGHT LOSS V. HEART DISEASE: Weight loss is determined by caloric intake. Heart disease is determined by dietary inflammatory components. True Quantification of Coronary Artery Disease Measured by AI Using FMTVDM. Archives of Medicine 10(5): 3.

22. Fleming RM, Fleming MR, McKusick A, Chaudhuri TK (2019) The Nuclear Imaging Uncertainty Principle. Do Our Nuclear Cameras Really Work? Open Acc J Oncol Med 3(1): 233-237.

23. Fleming RM, Fleming MR, Chaudhuri TK (2019) Restoring the Public Trust in the Patient Physician Relationship. Int J Nuclear Med Radioactive Subs 2(1): 000113.

24. Fleming RM, Fleming MR, Chaudhuri TK (2019) The Need to Actually Measure What We're Talking about before We Put it All Together. Int J Nuclear Med Radioactive Subs 2(1): 000114. 
25. Fleming RM, Fleming MR, McKusick A, Chaudhuri TK (2019) Objectively measuring popular diets effect on heart disease and breast cancer. Acta Sci Pharm Sci 3(9): 81-92.

26. Fleming RM (2000) The Natural Progression of Atherosclerosis in an Untreated Patient with Hyperlipidemia: Assessment via Cardiac PET Intern J Angiol 9(2): 70-73.
27. Matthew R (2000) Storks Deliver Babies ( $\mathrm{p}=0.008)$. Teaching Statistics 22(2): 36-38.

28. The Fleming Method for Tissue and Vascular Differentiation and Metabolism (FMTVDM) using same state single or sequential quantification comparisons.

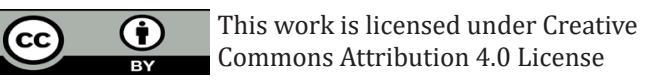

To Submit Your Article Click Here:

Submit Article

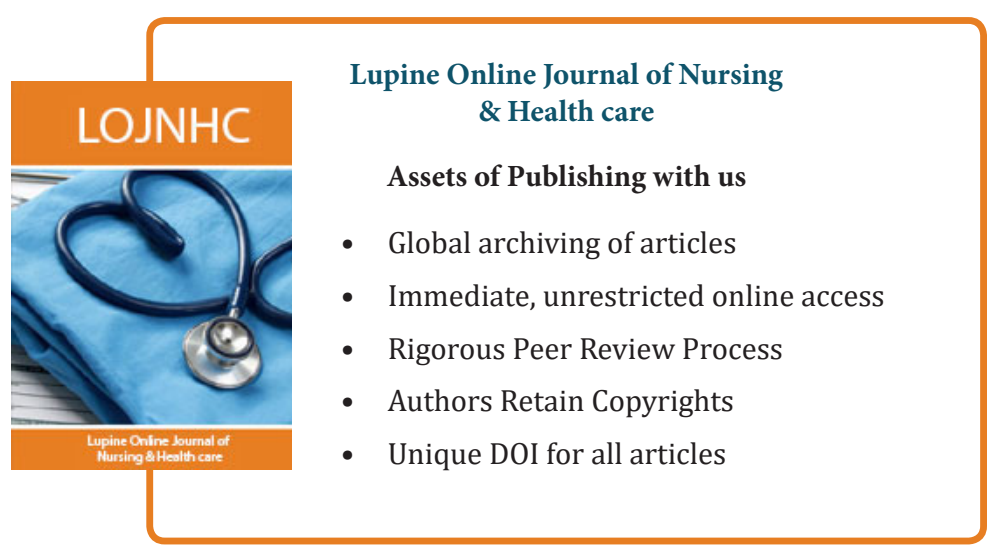

